\title{
Relief of Pain-Depressed Behavior in Rats by Activation of D1-Like Dopamine Receptors
}

\author{
Matthew F. Lazenka, Kelen C. Freitas, Sydney Henck, and S. Stevens Negus \\ Department of Pharmacology and Toxicology, Virginia Commonwealth University, Richmond, Virginia \\ Received February 17, 2017; accepted April 13, 2017
}

\begin{abstract}
Clinically significant pain often includes a decrease in both behavior and mesolimbic dopamine signaling. Indirect and/or direct dopamine receptor agonists may alleviate pain-related behavioral depression. To test this hypothesis, the present study compared effects of indirect and direct dopamine agonists in a preclinical assay of pain-depressed operant responding. Male Sprague-Dawley rats with chronic indwelling microelectrodes in the medial forebrain bundle were trained in an intracranial selfstimulation (ICSS) procedure to press a lever for pulses of electrical brain stimulation. Intraperitoneal injection of dilute lactic acid served as an acute noxious stimulus to depress ICSS. Intraperitoneal lactic acid-induced depression of ICSS was dose-dependently blocked by the dopamine transporter inhibitor methylphenidate and the D1-selective agonist SKF82958, but not by the D2/3-selective agonists quinpirole, pramipexole, or sumanirole. The antinociceptive effects of methylphenidate
\end{abstract}

and SKF82958 were blocked by the D1-selective antagonist SCH39166. Acid-induced stimulation of a stretching response was evaluated in separate groups of rats, but all agonists decreased acid-stimulated stretching, and antagonism experiments were inconclusive due to direct effects of the antagonists when administered alone. Taken together, these results suggest that D1-receptor stimulation is both sufficient to block acidinduced depression of ICSS and necessary for methylphenidate antinociception in this procedure. Conversely, D2/3-receptor stimulation is not sufficient to relieve pain-depressed behavior. These results support the hypothesis that pain-related depression of dopamine D1 receptor signaling contributes to painrelated depression of behavior in rats. Additionally, these results support further consideration of indirect dopamine agonists and direct $D 1$ receptor agonists as candidate treatments for painrelated behavioral depression.

\section{Introduction}

Pain is a significant public health problem (van Hecke et al., 2013; Nahin, 2015), and common comorbidities include anxiety and depression (Bair et al., 2003). Pain is also associated with impaired function and decreased behavior assessed clinically using questionnaires such as the Brief Pain Inventory (Dworkin et al., 2005), and impaired function is both a cardinal sign in pain diagnosis and a target of pain treatment (Negus, 2013). One factor that may contribute to pain-related depression of mood and behavior is depression of mesolimbic dopamine signaling and nucleus accumbens medium spiny neuron activity (Apkarian et al., 2013; Jensen et al., 2013; Francis and Lobo, 2017; Taylor et al., 2016). Both preclinical (Leitl et al., 2014) and clinical studies (Becerra et al., 2001; Wood et al., 2007; Baliki et al., 2010; Ledermann et al., 2016) have found decreases in basal dopamine output or decreased nucleus accumbens activity in pain states. Moreover, multiple studies suggest that loss of dopamine signaling can enhance pain (Saade et al., 1997; Chudler and $\mathrm{Lu}, 2008$ ), or that

This work was supported by the National Institutes of Health National Institute of Neurologic Disorders and Stroke [Grant R01 NS070715] and National Institute on Drug Abuse [Grant T32 DA007027].

https://doi.org/10.1124/jpet.117.240796. increases in dopamine signaling can reduce pain (Chudler and Dong, 1995; Altier and Stewart, 1999; Rosenberg et al., 2013). For example, pain is a common presentation of patients with Parkinson's disease (Ford, 2009; Sophie and Ford, 2012), and treatment with the dopamine precursor levodopa can alleviate pain in these patients (Gerdelat-Mas et al., 2007; Cury et al., 2016). Levodopa can also alleviate pain with other etiologies (Dickey and Minton, 1972; Ertas et al., 1998), and dopamine uptake inhibitors or releasers, such as bupropion, methylphenidate, or amphetamine, can also alleviate pain states in humans under some circumstances (Burrill et al., 1944; Semenchuk et al., 2001; Treister et al., 2015).

Dopamine acts at two different receptor subtype families, the D1-like (D1 and D5) and D2-like (D2, D3, D4) receptors. Although previous preclinical studies have investigated the analgesic potential of agonists or antagonists at these receptors, these studies have primarily been conducted with procedures measuring behaviors that increase in rate, frequency, or intensity after delivery of a noxious stimulus (i.e., "pain-stimulated" behaviors) (Paalzow and Paalzow, 1983; Barasi and Duggal, 1985; Michael-Titus et al., 1990; Munro, 2007). These assays are limited by at least two factors (Negus et al., 2006; Negus, 2013). First, drugs can decrease these behaviors by either decreasing sensitivity to the noxious stimulus or decreasing motor competence of the subject to

ABBREVIATIONS: ANOVA, analysis of variance; ICSS, intracranial self-stimulation; MCR, maximum control rate; SCH39166, (6aS-trans)-11Chloro-6,6a,7,8,9,13b-hexahydro-7-methyl-5H-benzo[d]naphth[2,1-b]azepin-12-ol hydrobromide; SKF82958, ( \pm )-6-Chloro-7,8-dihydroxy-3-allyl1-phenyl-2,3,4,5-tetrahydro-1H-3-benzazepine hydrobromide. 
emit the nocifensive response, and apparent antinociceptive effects of D2-like agonists may reflect motor disruption (Dourado et al., 2016). Second, these procedures do not measure drug effects on clinically relevant signs of pain that include functional impairment and behavioral depression.

This study tested effects of dopaminergic drugs in a preclinical assay in which the noxious stimulus decreases, rather than increases, the target behavior, and in which effective analgesics restore behavior. This type of procedure has been characterized as an assay of "pain-depressed behavior" (i.e., a procedure measuring behaviors that decrease in rate, frequency, or intensity after delivery of a noxious stimulus) (Negus et al., 2006; Negus, 2013). Specifically, the studies reported here examined pain-related depression of positively reinforced operant behavior in a procedure used previously in studies with other drug classes, including mu, kappa, and delta opioid receptor agonists (Pereira Do Carmo et al., 2009; Negus et al., 2010, 2012b; Altarifi et al., 2015; Brust et al., 2016); cannabinoids (Kwilasz and Negus, 2012; Kwilasz et al., 2014); nicotinic acetylcholine receptor agonists (Freitas et al., 2015); and N-methyl-D-aspartate (NMDA) receptor antagonists (Hillhouse and Negus, 2016). The current study was designed to extend this work in three ways. First, effects of the clinically available dopamine uptake inhibitor methylphenidate were examined. Second, effects of methylphenidate were compared with effects of the high-efficacy D1-like agonist SKF82958 [(土)-6-Chloro-7,8-dihydroxy-3-allyl-1-phenyl-2,3,4,5tetrahydro-1H-3-benzazepine hydrobromide] and three D2-like agonists that varied in selectivity for D2 versus D3 receptors (sumanirole, quinpirole, pramipexole). Last, sensitivity of methylphenidate effects to antagonism by the D1-like antagonist SCH39166 [(6aS-trans)-11-Chloro-6,6a,7,8,9,13b-hexahydro7-methyl-5H-benzo[d]naphth[2,1-b]azepin-12-ol hydrobromide] and the D2-like antagonist eticlopride was determined.

\section{Materials and Methods}

\section{Subjects}

A total of 79 adult male Sprague-Dawley rats (ENVIGO, Frederick, MD) were used to assess drug effects on pain-depressed and painstimulated behavior as described previously (Pereira Do Carmo et al., 2009; Negus, 2013; Rosenberg et al., 2013). All rats had ad libitum access to food and water and were housed individually on a 12-hour light-dark cycle ( 6 a.m. to 6 p.m., lights on) in a facility accredited by the Association for the Assessment and Accreditation of Laboratory Animal Care. Rats weighed between 300 and $350 \mathrm{~g}$ at the time of surgery for implantation of intracranial electrodes as described later. All experiments were approved by the Institutional Animal Care and Use Committee at Virginia Commonwealth University, and studies were conducted in accordance with the National Institutes of Health Guide for the Care and Use of Laboratory Animals, $8^{\text {th }}$ edition [National Research Council (U.S.), 2011].

\section{Assay of Intracranial Self-Stimulation}

Surgery. For surgery, anesthesia was accomplished using isoflurane (3\% in oxygen; Webster Veterinary, Phoenix, AZ) until rats were unresponsive to toe pinch. Each rat was placed in a stereotaxic apparatus, and the insulated cathode of a stainless steel electrode (Plastics One, Roanoke, VA) was implanted using the skull-flat method and previously published coordinates to target the medial forebrain bundle at the level of the lateral hypothalamus $(2.8 \mathrm{~mm}$ posterior to the bregma, $1.7 \mathrm{~mm}$ lateral to the midsagittal suture, and $8.8 \mathrm{~mm}$ ventral to the skull) (Paxinos and Watson, 1998; Lazenka et al., 2016). The uninsulated anode of the microelectrode was wrapped around one of three skull screws to act as a ground, and the electrode was secured to the skull using dental acrylic. Rats received ketoprofen $(5 \mathrm{mg} / \mathrm{kg}$, i.p.) as a postoperative analgesic immediately and 24 hours following surgery and were allowed to recover for at least 1 week before intracranial self-stimulation (ICSS) training.

Apparatus. Operant conditioning chambers $(29.2 \times 30.5 \times$ $24.1 \mathrm{~cm}$ ) were contained in sound-attenuating boxes (Med Associates, St. Albans, VT). Each chamber was equipped with a house light, a response lever, stimulus lights located above the lever, and an ICSS stimulator. During behavioral sessions, rats were placed into the chambers, and the electrode was connected to the ICSS stimulator via bipolar cables routed through a swivel commutator (model SL2C; Plastics One). A computer and associated software controlled stimulus presentations, recorded lever presses, and performed preliminary data analysis (Med Associates).

Training. The behavioral procedure was identical to that described previously (Rosenberg et al., 2013; Negus and Miller, 2014; Miller et al., 2015). Behavioral sessions began with onset of the house light, and lever-press responding under a fixed-ratio 1 schedule produced brain stimulation via the intracranial electrode. Each stimulation consisted of a 0.5 -second train of square-wave cathodal pulses ( $0.1 \mathrm{~ms}$ per pulse). The stimulus lights over the lever were illuminated, and responding had no scheduled consequences during brain stimulation. The stimulation frequency and intensity were set at $158 \mathrm{~Hz}$ and $150 \mu \mathrm{A}$, respectively, during the initial 60-minute training sessions. Stimulation intensity was then adjusted for each rat to a level that maintained reinforcement rates of at least 30 stimulations per minute. Changes in frequency were then introduced during sessions composed of three consecutive 10-minute components, each of which contained 10 consecutive 60 -second trials. The stimulation frequency ranged from $158 \mathrm{~Hz}$ in the first trial of each component to $56 \mathrm{~Hz}$ in the last trial, dropping in 0.05-log-unit steps from one trial to the next. Each trial consisted of a 10-second time-out period followed by a 50 -second response period. During the time-out period, responding had no scheduled consequences, and five noncontingent stimulations were delivered at the designated frequency for that trial. During the response period, responding under the fixed-ratio 1 schedule produced brain stimulation and illumination of the lever lights. Training was considered to be complete when ICSS frequency-rate curves were statistically similar for 3 consecutive days of training as indicated two-way analysis of variance (ANOVA) with frequency of brain stimulation and day of training as the main effect variables (see Data Analysis). Rats that did not meet the criteria for ICSS studies within 6 weeks were assigned to studies of acid-stimulated stretching (discussed later).

Testing. Test sessions consisted of three consecutive baseline components followed first by a treatment period and then by a series of test components. Three general types of test sessions were conducted that varied details of the treatment period and test components. First, the potency and time course of effects produced by methylphenidate in the absence of a noxious stimulus were determined as previously described for other drugs that target monoamine transporters (Bauer et al., 2013; Rosenberg et al., 2013; Bonano et al., 2014; Miller et al., 2015). For dose-effect studies, a 10-minute treatment period was followed by two test components, and methylphenidate $(0.1-10 \mathrm{mg} / \mathrm{kg})$ was administered at the beginning of the treatment period. For time-course studies, administration of $3.2 \mathrm{mg} / \mathrm{kg}$ methylphenidate was followed by pairs of test components beginning $10,30,100$, and 300 minutes after drug administration.

Second, drug effects on acid-induced depression of ICSS were examined as previously described with other classes of drugs, including mu, kappa, and delta opioid receptor agonists (Pereira Do Carmo et al., 2009; Negus et al., 2010, 2012b; Altarifi et al., 2015); monoamine transporter inhibitors (Rosenberg et al., 2013; Miller et al., 2015); cannabinoids (Kwilasz and Negus, 2012; Kwilasz et al., 
2014); nicotinic acetylcholine receptor agonists (Freitas et al., 2015); and N-methyl-D-aspartate (NMDA) receptor antagonists (Hillhouse and Negus, 2016). For these studies, a 10-minute treatment period was followed by two test components, and test drug and $1.8 \%$ lactic acid were administered at the beginning and end of the treatment period, respectively. Test drugs and doses were as follows: methylphenidate $(0.1-1.0 \mathrm{mg} / \mathrm{kg})$, SKF82958 $(0.01-0.1 \mathrm{mg} / \mathrm{kg})$, quinpirole $(0.0032-0.32 \mathrm{mg} / \mathrm{kg})$, pramipexole $(0.0032-0.032 \mathrm{mg} / \mathrm{kg})$, and sumanirole $(0.032-1.0 \mathrm{mg} / \mathrm{kg})$. Effects of dopamine receptor agonists on ICSS in the absence of the noxious stimulus were reported previously (Lazenka et al., 2016).

Last, for antagonist studies with methylphenidate, a 30-minute treatment period was followed by two test components. A dopamine receptor antagonist (SCH39166, 0.01-0.032 mg/kg; eticlopride, $0.01-0.032 \mathrm{mg} / \mathrm{kg}$ ) was administered at the beginning of the treatment period, $0.32 \mathrm{mg} / \mathrm{kg}$ methylphenidate was administered 20 minutes later, and $1.8 \%$ lactic acid was administered at the end of the treatment period.

Test sessions were conducted on Tuesdays and Fridays, and threecomponent training sessions were conducted on other weekdays. For each drug, dose order was varied using a pseudo Latin-square design, and testing occurred in a group of five to six rats. Agonist and doses and pretreatment times were based on previous studies (Caine and Koob, 1994; Li et al., 2006; Lazenka et al., 2016) and preliminary results.

Data Analysis. For the purposes of data analysis, the first baseline component of each test session was considered a "warm up" component, and data were discarded. The primary dependent variable was reinforcement rate in stimulations per minute during each frequency trial for the second and third baseline components and for all test components. To normalize these data, raw reinforcement rates from each trial in each rat were converted to percent maximum control rate (\% MCR) for that rat. MCR was defined as the mean of the maximal rates observed during the second and third baseline components of that test session. Subsequently, \% MCR values for each trial were calculated as [(reinforcement rate during a frequency trial $) /(M C R)] \times 100$. For each rat, data from baseline and test components were averaged to yield baseline and test frequency-rate curves. Baseline and test data were then averaged across rats to yield mean baseline and test frequency-rate curves for each manipulation. Results were compared by repeated-measures two-way ANOVA with ICSS frequency as one factor and either dose or time as the second factor. A significant ANOVA was followed by the Holm-Sidak post-hoc test, and the criterion for significance was $P<0.05$.

To provide an additional summary measure of ICSS performance, the total number of stimulations per component was determined across all 10 frequency trials of each component. Test data were expressed as a percentage of the average number of total stimulations per component earned during the second and third baseline components for that day. Therefore, percent baseline stimulation was calculated as (mean total stimulations during test components/mean total stimulations during baseline components $) \times 100$. These data were then averaged across rats for each experimental manipulation. Data for the potency or time course of any one drug were compared by one-way ANOVA, with dose or time as the single factor. For antagonism studies, data were analyzed by two-way ANOVA, with methylphenidate dose and antagonist dose as the two factors. A significant one- or two-way ANOVA was followed by Dunnett's or Holm-Sidak post-hoc test, respectively, and the criterion for significance was $P<0.05$. Data for vehicle and SKF82958 effects after SCH39166 pretreatment were compared by $t$ test. Additionally, to calculate the $\mathrm{ED}_{50}$ values and $95 \%$ confidence limits for dose-effect data, percent baseline stimulation values were transformed using the following equation: \% acid blockade $=[$ (drug-vehicle $) /($ baselinevehicle) $\times 100$, where "drug" refers to data collected after administration of a given drug dose + acid, "vehicle" refers to data collected after vehicle + acid, and "baseline" refers to data in the absence of drug or acid. Transformed data were then analyzed by linear regression utilizing Excel (Microsoft, Redmond, WA), and the $\mathrm{ED}_{50}$ was defined as the effective dose producing $50 \%$ blockade of acidinduced depression of ICSS. $\mathrm{ED}_{50}$ values were considered to be significantly different if $95 \%$ confidence limits did not overlap. A value of $100 \%$ acid blockade indicated complete blockade of acidinduced depression of ICSS. Values greater than $100 \%$ acid blockade indicated facilitation of ICSS above baseline levels, and values below $0 \%$ indicated exacerbation of acid-induced depression of ICSS.

\section{Assay of Acid-Stimulated Stretching}

Behavioral Procedure. To complement studies in the assay of acid-depressed ICSS, rats that failed to meet ICSS training criteria were used in studies of lactic acid-stimulated stretching as described previously (Altarifi et al., 2015; Freitas et al., 2016; Hillhouse and Negus, 2016). During test sessions, administration of test drug(s) was followed first by a pretreatment interval identical to those used for ICSS studies and then by injection of $1.8 \%$ lactic acid. Immediately after the acid injection, rats were placed into an amber acrylic test chamber $(31.0 \times 20.1 \times 20.0 \mathrm{~cm})$ for a 30 -minute observation period, and the number of stretches was counted. A stretch was operationally defined as a contraction of the abdomen followed by extension of the hindlimbs. Initial studies evaluated effects of methylphenidate $(0.1-10 \mathrm{mg} / \mathrm{kg}), \mathrm{SKF} 82958(0.032-0.32 \mathrm{mg} / \mathrm{kg})$, and quinpirole $(0.00032-0.32 \mathrm{mg} / \mathrm{kg})$. In subsequent antagonism experiments, effects of $0.32 \mathrm{mg} / \mathrm{kg}$ methylphenidate were redetermined after pretreatment with $0.0032-0.01 \mathrm{mg} / \mathrm{kg}$ SCH39166 or $0.0032-0.01 \mathrm{mg} / \mathrm{kg}$ eticlopride. Dose order across rats was counterbalanced using a pseudo Latinsquare design, and at least 48 hours separated test sessions for each rat. Rats were drug naïve for the start of each study, and the experimenter who scored stretching was blind to the drug treatments. All rats were initially tested twice with acid alone, and only rats that exhibited greater than 10 mean stretches during these sessions were included in this study.

Data Analysis. The primary dependent variable was the number of stretches counted during each observation period in each rat. Data for the potency of any one drug were compared by one-way ANOVA, with dose as the single factor. For antagonism studies, data were analyzed by two-way ANOVA, with methylphenidate dose and antagonist dose as the two factors. A significant one- or two-way ANOVA was followed by Dunnett's or Holm-Sidak post-hoc test, respectively, and the criterion for significance was $P<0.05$. To calculate the $\mathrm{ED}_{50}$ values and $95 \%$ confidence intervals for dose-effect data, raw stretches were transformed using the following equation: \% acid blockade $=[($ vehicle-drug $) /$ vehicle $] \times 100$, where "drug" and "vehicle" were defined as the number of stretches observed after administration of a given drug dose or vehicle, respectively, before acid. Transformed data were then analyzed by linear regression utilizing Microsoft Excel, and the $\mathrm{ED}_{50}$ was defined as the effective dose producing $50 \%$ blockade of acid-stimulated stretching. $\mathrm{ED}_{50}$ values were considered to be significantly different if $95 \%$ confidence intervals did not overlap.

\section{Drugs}

SCH39166 HBr [(6aS-trans)-11-chloro-6,6a,7,8,9,13b-hexahydro7-methyl-5H-benzo[ $d]$ naphth[2,1-b]azepin-12-ol hydrobromide], eticlopride $\mathrm{HCl}$, pramipexole $2 \mathrm{HCl}$, and sumanirole maleate were obtained from Tocris (Minneapolis, MN). (-)-Quinpirole $\mathrm{HCl}$ was purchased from Sigma-Aldrich (St. Louis, MO). ( \pm )SKF82958 $\mathrm{HBr}$ [( \pm )-6-chloro-7,8-dihydroxy-3-allyl-1-phenyl-2,3,4,5-tetrahydro-1H-3benzazepine hydrobromide] was provided by the National Institute of Mental Health Chemical Synthesis and Drug Supply Program (Bethesda, MD). ( \pm )-Methylphenidate $\mathrm{HCl}$ was provided by the National Institute on Drug Abuse Drug Supply Program (Bethesda, MD). All drugs were dissolved in $0.9 \%$ bacteriostatic saline (Patterson Veterinary, Richmond, VA) and administered i.p. in a volume of $1 \mathrm{ml} / \mathrm{kg}$. 


\section{Results}

Effects of Methylphenidate Alone on ICSS. Electrical brain stimulation maintained a frequency-dependent increase in ICSS rates during baseline ICSS components. The mean \pm S.E.M. MCR for all rats in the study was $60 \pm 1.2$ stimulations per trial, and the mean \pm S.E.M. number of baseline total stimulations per component was $260 \pm 10.2$. Figure 1 shows that methylphenidate produced a dose- and time-dependent increase in ICSS in the absence of the acid noxious stimulus. Supportive statistical results are shown in the figure legends. A dose of $0.1 \mathrm{mg} / \mathrm{kg}$ methylphenidate had no effect on the ICSS frequency-rate curve (Fig. 1A) and did not alter the summary measure of percent baseline stimulations per component (Fig. 1B). A higher dose of $0.32 \mathrm{mg} / \mathrm{kg}$ methylphenidate increased
ICSS rates maintained by two frequencies of brain stimulation in analysis of frequency-rate curves $(79$ and $89 \mathrm{~Hz})$ but did not significantly alter percent baseline stimulations. Higher methylphenidate doses increased ICSS across a broader range of frequencies in analysis of frequency-rate curves and significantly increased percent baseline total stimulations. Based on these initial studies, the time course of $3.2 \mathrm{mg} / \mathrm{kg}$ was tested. At this dose, the peak effects of methylphenidate were seen at 10 minutes, which was the same pretreatment time as the dose-effect studies, and responding returned to baseline within 100 minutes (Fig. $1 \mathrm{C}$ and $\mathrm{D})$.

Effects of Methylphenidate on Acid-Induced Depression of ICSS. Figure 2 shows that methylphenidate dose-dependently blocked acid-induced depression of ICSS, and the $\mathrm{ED}_{50}$
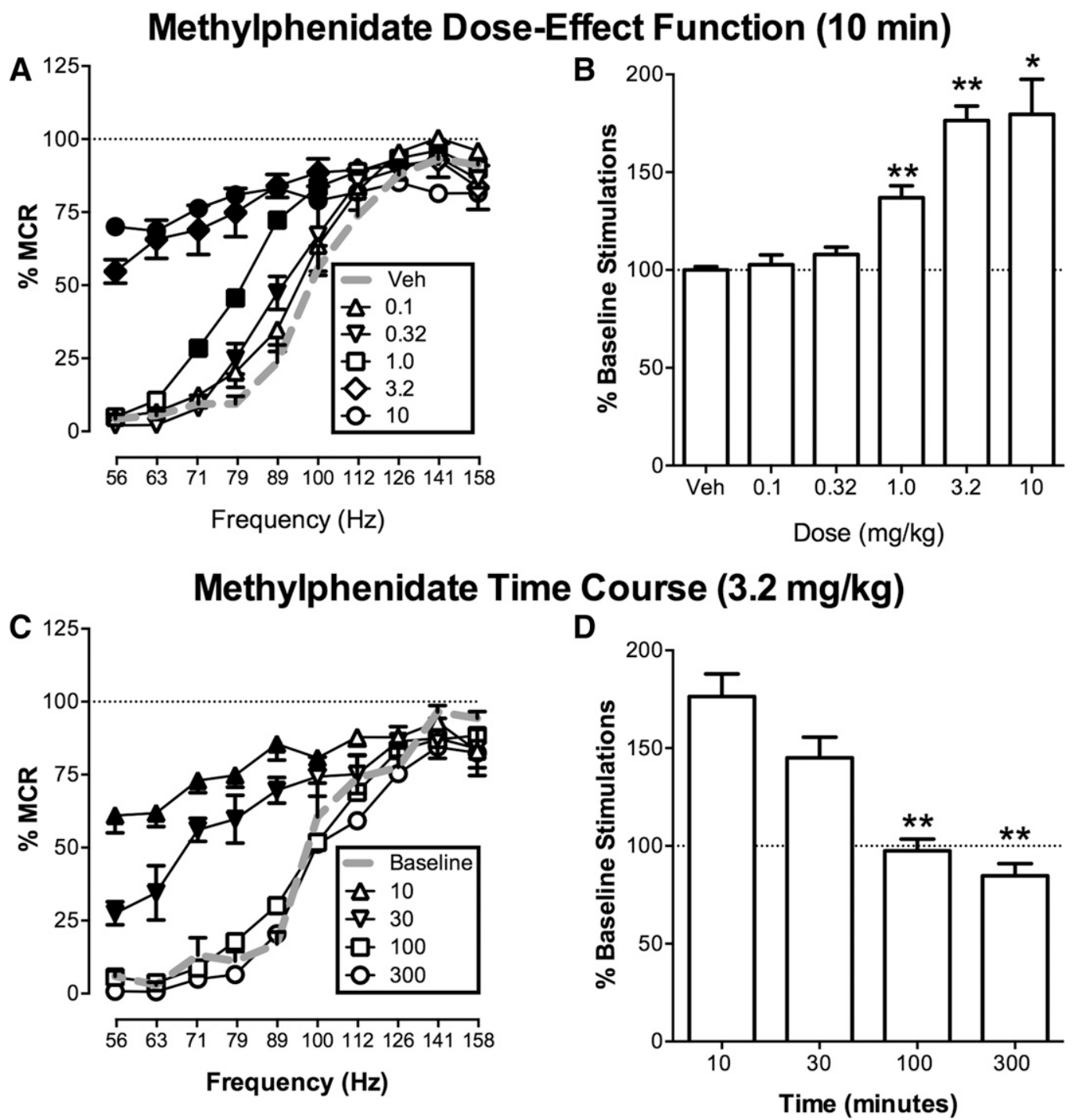

Fig. 1. Effects of methylphenidate on intracranial self-stimulation in the absence of the acid noxious stimulus. (A and C) Full ICSS frequency-rate curves. Abscissae: frequency of electrical brain stimulation in Hertz (log scale). Ordinates: \% MCR. Filled symbols show significant differences from vehicle (Veh) (A) and baseline (C) as determined by repeated-measures two-way ANOVA followed by the Holm-Sidak post-hoc test $(P<0.05)$. (B and D) Summary measure of the total number of stimulations per component. Abscissae: dose in $\mathrm{mg} / \mathrm{kg}$ (B) or time post injection in minutes (log scale) (D). Ordinates: percent baseline stimulations per component. Asterisks show significant difference compared with vehicle or 10 minutes as determined by repeated-measures one-way ANOVA followed by Dunnett's post-hoc test $(* P<0.05 ; * * P<0.01)$. Data presented are the mean \pm S.E.M. of six rats. Statistical results are as follows. (A) Significant main effects of frequency $[\mathrm{F}(9,45)=164.4, P<0.0001]$ and dose $[\mathrm{F}(4,20)=32.5, P<0.0001]$ and a significant interaction $[\mathrm{F}(36,180)=9.5, P<0.0001]$. (B) Significant effect of dose $[\mathrm{F}(1.65,8.25)=18.4, P<0.01)]$. (C) Significant main effect of frequency $[\mathrm{F}(9,45)=60.2, P<0.0001]$ and time $[\mathrm{F}(4,20)=31.6, P<0.0001]$ and a significant interaction $[\mathrm{F}(36,180)=8.3, P>0.0001]$. (D) Significant effect of time $[\mathrm{F}(3,20)=22.61, P<0.0001]$. 


\section{Methylphenidate $+1.8 \%$ lactic acid}
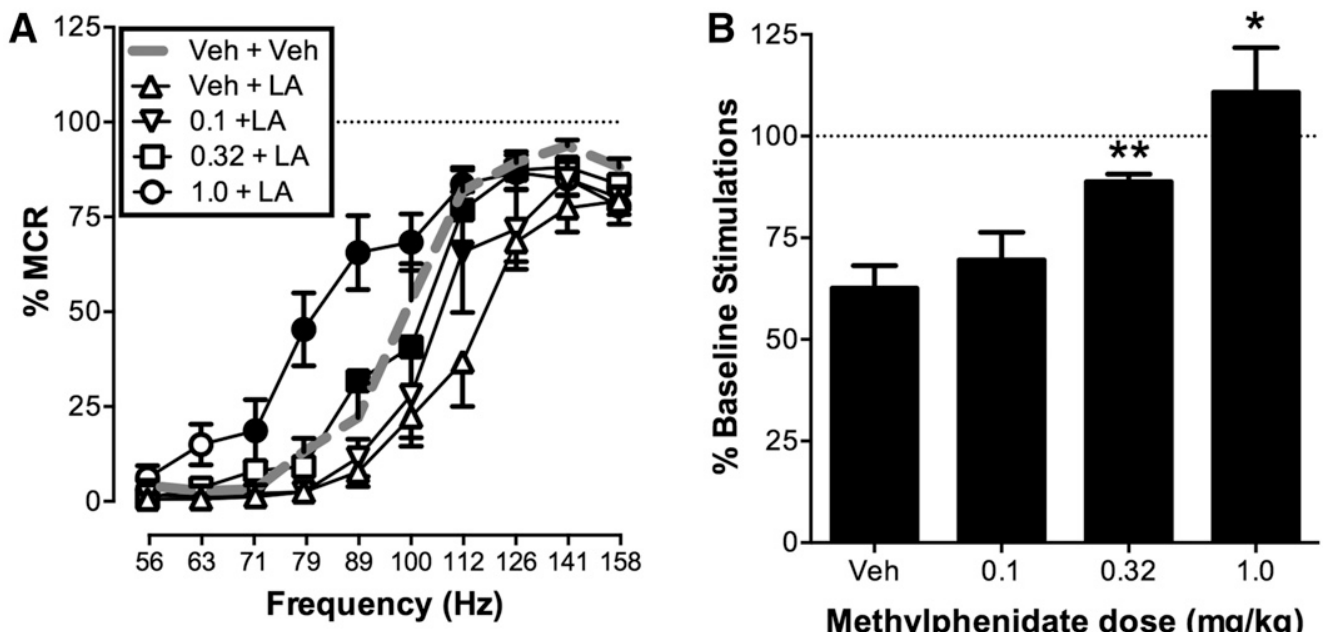

Antagonism of Methylphenidate
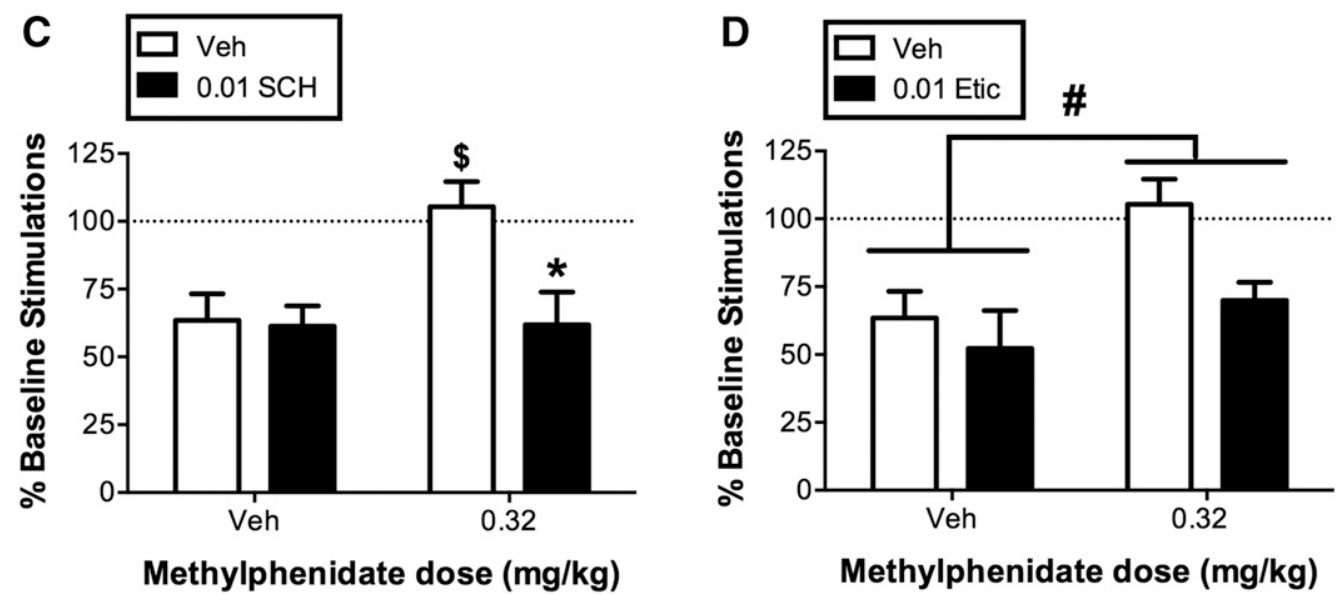

Fig. 2. Effects of methylphenidate on acid-induced depression of ICSS in the absence or presence of dopamine receptor antagonists. (A) Full frequencyrate curves. Abscissae: frequency of electrical brain stimulation in Hertz (log scale). Ordinates: \% MCR. Filled symbols show significant differences from vehicle plus $1.8 \%$ lactic acid (Veh + LA) as determined by repeated-measures two-way ANOVA followed by the Holm-Sidak post-hoc test $(P<0.05)$. (B) Summary measure of baseline stimulations per component. Abscissae: dose in $\mathrm{mg} / \mathrm{kg}$ (log scale). Ordinates: percent baseline stimulation per component. Asterisks show significant difference compared with vehicle plus 1.8\% lactic acid following a repeated-measures one-way ANOVA followed by Dunnett's post-hoc test $(* P<0.05$; $* * P<0.01)$. (C and D) Effects of the D1 antagonist SCH39166 (SCH) or the D2/3 antagonist eticlopride (Etic) on methylphenidate antinociception. Abscissae: dose of methylphenidate in $\mathrm{mg} / \mathrm{kg}$. Ordinates: percent baseline stimulations per component. (C) \$Significant difference between effects of Veh + Veh and Veh $+0.32 \mathrm{mg} / \mathrm{kg}$ methylphenidate; *Significant difference between Veh $+0.32 \mathrm{mg} / \mathrm{kg}$ methylphenidate and $0.01 \mathrm{mg} / \mathrm{kg}$ SCH39166 + $0.32 \mathrm{mg} / \mathrm{kg}$ methylphenidate, as determined by repeated-measures two-way ANOVA followed by the Holm-Sidak post-hoc test $(P<0.05)$. (D) " Significant main effect of methylphenidate dose as determined by two-way ANOVA. Data presented are the mean \pm S.E.M. of five rats, and identical data are used for antagonist vehicle in (C) and (D) because both drugs used the same vehicle. Statistical results are as follows. (A) Significant main effects of frequency $[\mathrm{F}(9,36)=176.4, P<0.0001]$ and dose $[\mathrm{F}(4,16)=13.2, P<0.0001]$ and a significant interaction $[\mathrm{F}$ $(36,144)=4.0, P<0.0001]$. (B) Significant effect of dose $[\mathrm{F}(1.8,7.2)=12.7, P<0.01)]$. (C) Significant main effects of methylphenidate dose $[\mathrm{F}(1,4)=$ 11.31, $P<0.05]$ and SCH39166 dose $[\mathrm{F}(1,4)=41.88, P<0.01]$ and a significant interaction $[\mathrm{F}(1,4)=9.750, P<0.05]$. (D) Significant main effects of methylphenidate dose $[\mathrm{F}(1,4)=14.55, P<0.05]$ and eticlopride dose $[\mathrm{F}(1,4)=10.96, P<0.05]$, but the interaction was not significant $[\mathrm{F}(1,4)=1.162$, $P=0.27]$

value is shown in Table 1. Administration of i.p. lactic acid alone produced a rightward shift in the ICSS frequency curve (Fig. 2A, compare "Veh + Veh" and "Veh + LA") and a decrease in the summary measure of percent baseline stimulations (Fig. 2B). Relative to the effects of acid alone, $0.1 \mathrm{mg} / \mathrm{kg}$ methylphenidate pretreatment increased ICSS rates at one frequency $(112 \mathrm{~Hz})$ but did not significantly increase percent baseline stimulations. Higher doses of 0.32 and $1.0 \mathrm{mg} / \mathrm{kg}$ methylphenidate increased ICSS rates across a broader range of frequencies in analysis of frequency-rate curves and significantly increased percent baseline stimulations. Notably, $0.32 \mathrm{mg} / \mathrm{kg}$ methylphenidate produced nearly full blockade of acid-induced depression of ICSS, such that responding after $0.32 \mathrm{mg} / \mathrm{kg}$ methylphenidate + acid was similar to responding after control treatment with vehicle + vehicle.

Figure 2 also shows the effects of the D1 antagonist SCH39166 (Fig. 2C) and the D2/D3 antagonist eticlopride (Fig. 2D) on acid-induced depression of ICSS in both the absence and presence of $0.32 \mathrm{mg} / \mathrm{kg}$ methylphenidate. A dose 
TABLE 1

$\mathrm{ED}_{50}$ values in $\mathrm{mg} / \mathrm{kg}$ (95\% confidence intervals) for methylphenidate, SKF82958, and quinpirole in the assays of acid-depressed ICSS and acidstimulated stretching

"Inactive" indicates a failure to produce at least $50 \%$ blockade in acid-depressed ICSS. The D2-preferring agonist sumanirole and the D3-preferring agonist pramipexole were inactive in acid-depressed ICSS and were not tested in acid-stimulated stretching.

\begin{tabular}{lcc}
\hline & Acid-Depressed ICSS & Acid-Stimulated Stretching \\
\hline Drug & $\mathrm{ED}_{50}(95 \% \mathrm{CI})$ & $\mathrm{ED}_{50}(95 \% \mathrm{CI})$ \\
Methylphenidate & $0.20(0.13-0.30)$ & $1.02(0.62-1.66)$ \\
SKF82958 & $0.020(0.0067-0.060)$ & $0.035(0.020-0.060)$ \\
Quinpirole & Inactive & $0.0043(0.0018-0.010)$
\end{tabular}

95\% CI, 95\% confidence interval

of $0.01 \mathrm{mg} / \mathrm{kg}$ SCH39166 had no effect on acid-induced depression of ICSS in the absence of methylphenidate. As noted earlier, $0.32 \mathrm{mg} / \mathrm{kg}$ methylphenidate blocked acidinduced depression of ICSS, and $0.01 \mathrm{mg} / \mathrm{kg}$ SCH39166 significantly antagonized this antinociceptive effect of methylphenidate. Effects of eticlopride were qualitatively similar, and overall, there were main effects of both methylphenidate increasing ICSS (indicated by the \# symbol in the figure) and of eticlopride decreasing ICSS; however, the interaction effect of the two-way ANOVA did not reach criteria for statistical significance, so post-hoc tests were not conducted. Higher doses of $0.032 \mathrm{mg} / \mathrm{kg} \mathrm{SCH} 39166$ and eticlopride were also evaluated. Effects of this higher SCH39166 dose were similar to effects shown in Fig. 2C; however, the higher eticlopride dose exacerbated acid-induced depression of ICSS in the absence of methylphenidate, precluding evaluation of its effects as an antagonist of methylphenidate (data not shown).

Effects of Dopamine D1 and D2/D3 Agonists on Acid-Induced Depression of ICSS. Figure 3 shows changes in acid-induced depression of ICSS produced by dopamine receptor agonists that differ in their selectivity for either dopamine D1 or D2/3 receptors. The D1 agonist SKF82958 (Fig. 3, A and B) dose-dependently blocked acid-induced depression of ICSS in a manner similar to methylphenidate, and its $\mathrm{ED}_{50}$ value is shown in Table 1. Moreover, this antinociceptive effect of SKF82958 was blocked by $0.01 \mathrm{mg} / \mathrm{kg}$ SCH39166. Thus, in rats pretreated with $0.01 \mathrm{mg} / \mathrm{kg}$ SCH39166, $0.1 \mathrm{mg} / \mathrm{kg}$ SKF82958 failed to block acid-induced depression of ICSS (percent baseline stimulations \pm S.E.M. $=48.02 \pm 9.06$ and $72.84 \pm 13.24$ after vehicle + acid or SKF82958 + acid, respectively; $t(14)=1.55$; $P=0.14$ ). In contrast, the D2/D3 agonist quinpirole (Fig. 3, $\mathrm{C}$ and D), the D3-preferring agonist pramipexole (Fig. 3, E and F), and the D2-preferring agonist sumanirole (Fig. 3, G and H) failed to block acid-induced depression of ICSS. Rather, as indicated by analysis of full frequency-rate curves in Fig. 3, C, E, and G, all three D2-like agonists dose-dependently exacerbated acid-induced depression of ICSS at high brain-stimulation frequencies.

Effects of Methylphenidate and Dopamine D1 and D2/D3 Agonists on Acid-Stimulated Stretching. In addition to producing depression of ICSS, the i.p. acid noxious stimulus also stimulates a stretching response in rats. Figure 4A shows that methylphenidate, SKF82958, and quinpirole all produced dose-dependent decreases in acidstimulated stretching, and $\mathrm{ED}_{50}$ values are shown in Table 1. Antagonism studies were initially conducted using $0.01 \mathrm{mg} / \mathrm{kg}$ for both SCH39166 and eticlopride, identical to the dose of each antagonist used in Fig. 2; however, this dose of each antagonist significantly decreased stretching when administered alone, and stretching after each antagonist $+0.32 \mathrm{mg} / \mathrm{kg}$ methylphenidate was not different from the decreased level of stretching observed after each antagonist administered alone (data not shown). Figure 4 shows the effects of a lower dose of $0.0032 \mathrm{mg} / \mathrm{kg}$ SCH39166 or eticlopride on acidstimulated stretching in both the absence and presence of $0.32 \mathrm{mg} / \mathrm{kg}$ methylphenidate. At this lower dose, neither antagonist significantly altered stretching in the absence of methylphenidate, but this dose also failed to block effects of methylphenidate.

\section{Discussion}

This study compared the roles of D1-like and D2-like dopamine receptors in mediating relief of pain-depressed behavior in rats. There were three main findings. First, in agreement with previous studies that evaluated other indirect dopamine agonists (Gatch et al., 1998, 1999; Rosenberg et al., 2013), methylphenidate produced a dose-dependent relief of acid-induced decreases in ICSS. Second, studies with selective antagonists indicated that D1 receptors were necessary for methylphenidate antinociception in the assay of aciddepressed ICSS. Last, studies with selective dopamine receptor agonists suggested that activation of D1-like receptors, but not D2-like receptors, was also sufficient to mimic antinociceptive effects of methylphenidate. Overall, these results suggest that indirect dopamine agonists and D1 agonists may warrant consideration as candidate treatments for functional impairment and decreased behavior associated with pain.

Methylphenidate effectiveness in relieving acid-induced increases in stretching and decreases in ICSS agrees with the previous finding that methylphenidate reduced painstimulated behaviors elicited by intraplantar formalin administration in rats (Dalal and Melzack, 1998). The methylphenidate potencies to reduce acid-stimulated stretching and formalin-stimulated behaviors were similar; however, methylphenidate was significantly more potent in the assay of acid-depressed ICSS than in either assay of pain-stimulated behavior. Other dopamine transporter blockers (e.g. bupropion and cocaine) are also generally more potent in blocking acid-induced decreases in ICSS than acid-stimulated stretching (Negus et al., 2012a; Rosenberg et al., 2013). One implication of this finding is that dopamine transporter inhibitors, such as methylphenidate, might be more effective in relieving signs of pain-related behavioral impairment than other signs of pain. This may be related to the principal clinical use of methylphenidate to reduce cognitive impairments and fatigue produced by opioid analgesics in treatment of cancerrelated pain (Bruera et al., 1989; Mucke et al., 2015), but not for treatment of pain directly. However, a recent clinical study found that methylphenidate enhanced morphine effects on subjective reports and measures of "pain interference in daily life" (Yamamotova et al., 2016), which agrees with preclinical studies suggesting synergistic antinociceptive interactions between methylphenidate and mu agonists (Dalal and Melzack, 1998; Halladay et al., 2009). Additionally, patients with attention-deficit hyperactivity disorder displayed higher sensitivity to experimental cold pain than did controls, and 

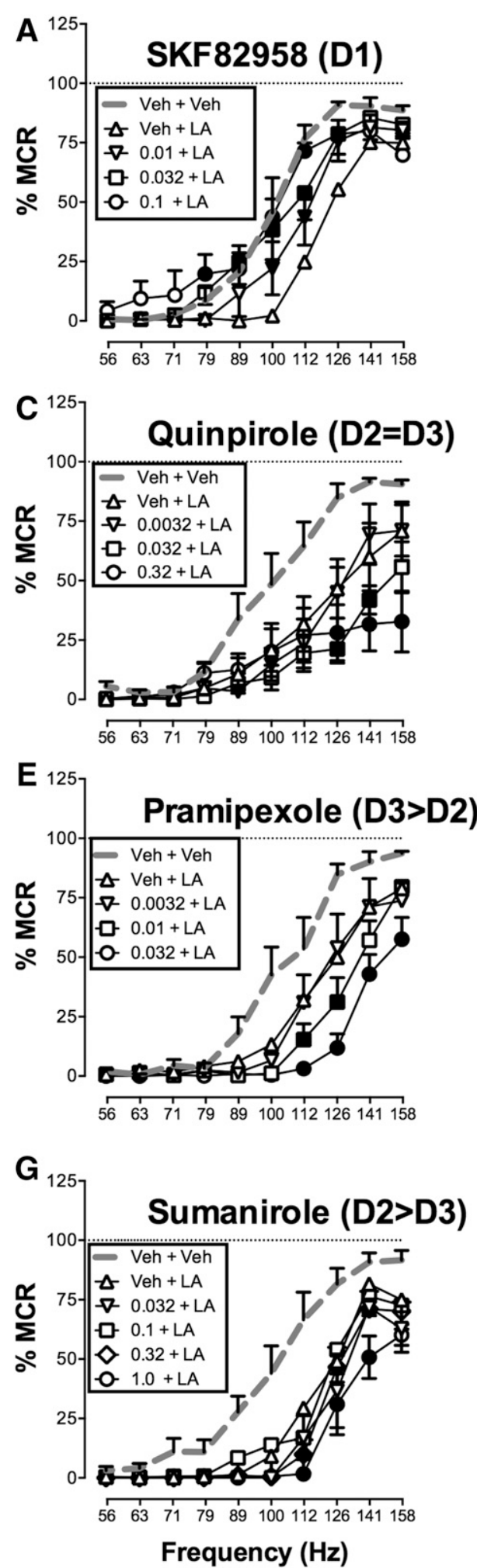
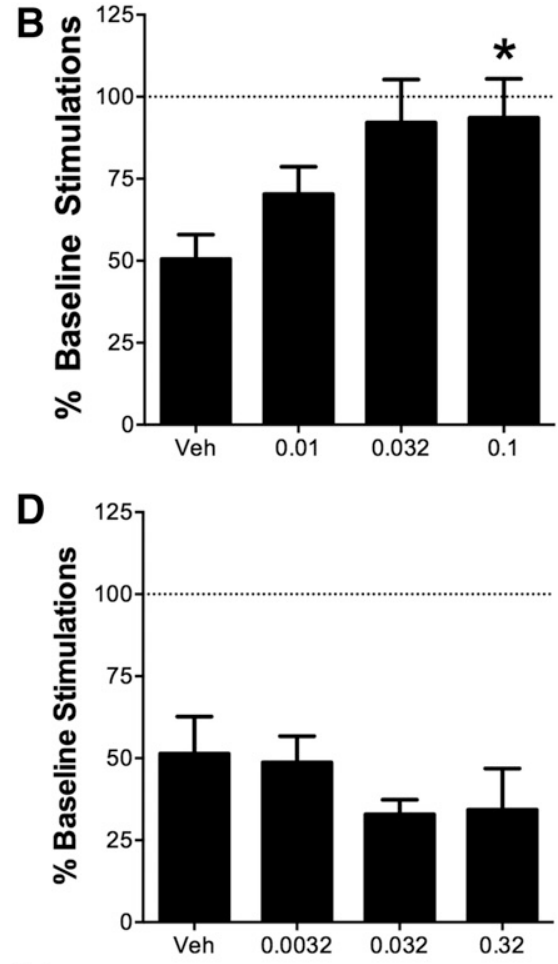

$\mathbf{F}$
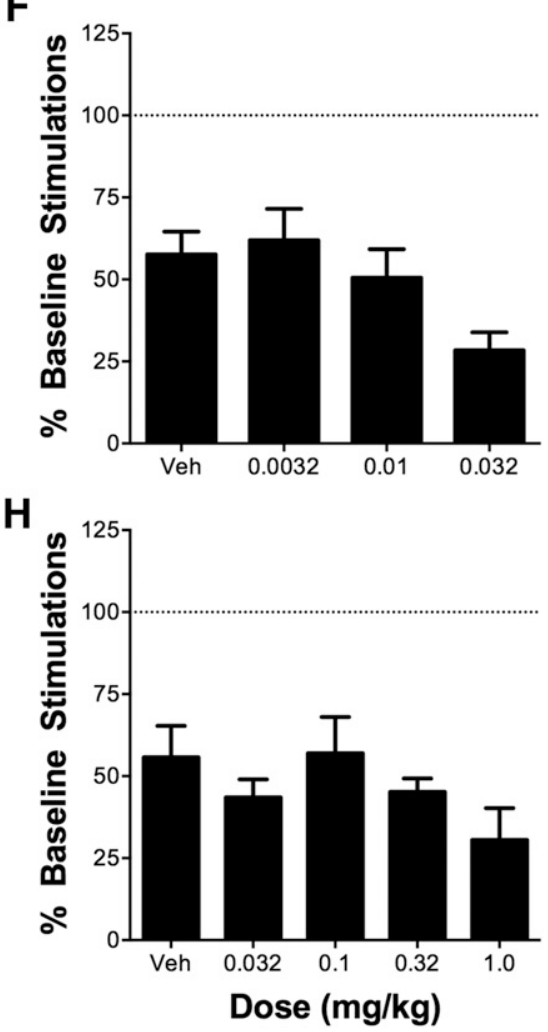

Fig. 3. Effects of dopamine receptor agonists on acid-induced depression of ICSS. (A, C, E, G) Full frequency-rate curves. Abscissae: frequency of electrical brain stimulation in Hertz (log scale). Ordinates: \% MCR. Filled symbols show significant differences from vehicle plus $1.8 \%$ lactic acid (Veh + LA) as determined by repeated-measures two-way ANOVA followed by the Holm-Sidak post-hoc test $(P<0.05)$. (B, D, F, H) Summary measure of baseline stimulations per component. Abscissae: dose of drug in $\mathrm{mg} / \mathrm{kg}$ (log scale). Ordinates: percent baseline stimulation per component. Asterisks show significant difference compared with vehicle plus $1.8 \%$ lactic acid (Veh) as determined by a repeated-measures one-way ANOVA followed by Dunnett's post-hoc test $(* P<0.05)$. Data presented are the mean \pm S.E.M. of six to seven rats. Statistical results are as follows. (A) Significant main effects of frequency $[\mathrm{F}(9,45)=130.4, P<0.0001]$ and dose $[\mathrm{F}(4,20)=4.8, P<0.01]$ and a significant interaction $[\mathrm{F}(36,180)=3.0, P<0.0001]$. (B) Significant effect of dose $[\mathrm{F}(2.4,11.9)=5.1, P<$ $0.01)]$. (C) Significant main effects of frequency [F $(9,54)=36.1, P<0.0001]$ and dose $[\mathrm{F}(4,24)=14.3$, $P<0.0001]$ and a significant interaction $[\mathrm{F}(36$, $216)=5.3, P<0.0001]$. (D) One-way ANOVA was not significant. (E) Significant main effects of frequency $[\mathrm{F}(9,45)=65.8, P<0.0001]$ and dose $[\mathrm{F}(4,20)=12.2, P<0.0001]$ and a significant interaction $[\mathrm{F}(36,180)=4.5, P<0.0001]$. (F) Oneway ANOVA was not significant. (G) Significant main effect of frequency $[\mathrm{F}(9,45)=54.8, P<$ $0.0001]$ and dose $[\mathrm{F}(5,25)=13.3, P<0.0001]$ and a significant interaction $[\mathrm{F}(45,225)=2.7, P<$ 0.0001]. (H) One-way ANOVA was not significant. methylphenidate reversed this cold hypersensitivity (Treister et al., 2015). Thus, methylphenidate may have true analgesic effects and enhance the analgesic effects of mu agonists in addition to alleviating undesirable mu agonist side effects, such as sedation.

Methylphenidate blocks norepinephrine transporters in addition to dopamine transporters (McLaughlin et al., 2017), and norepinephrine uptake inhibition may also play a role in the antinociceptive/analgesic effects of monoamine transporter inhibitors (Beydoun and Backonja, 2003). However, two findings suggest that methylphenidate antinociception in the assay of acid-depressed ICSS likely reflected dopaminergic effects rather than noradrenergic effects. First, previous studies found that acid-induced decreases in ICSS were 

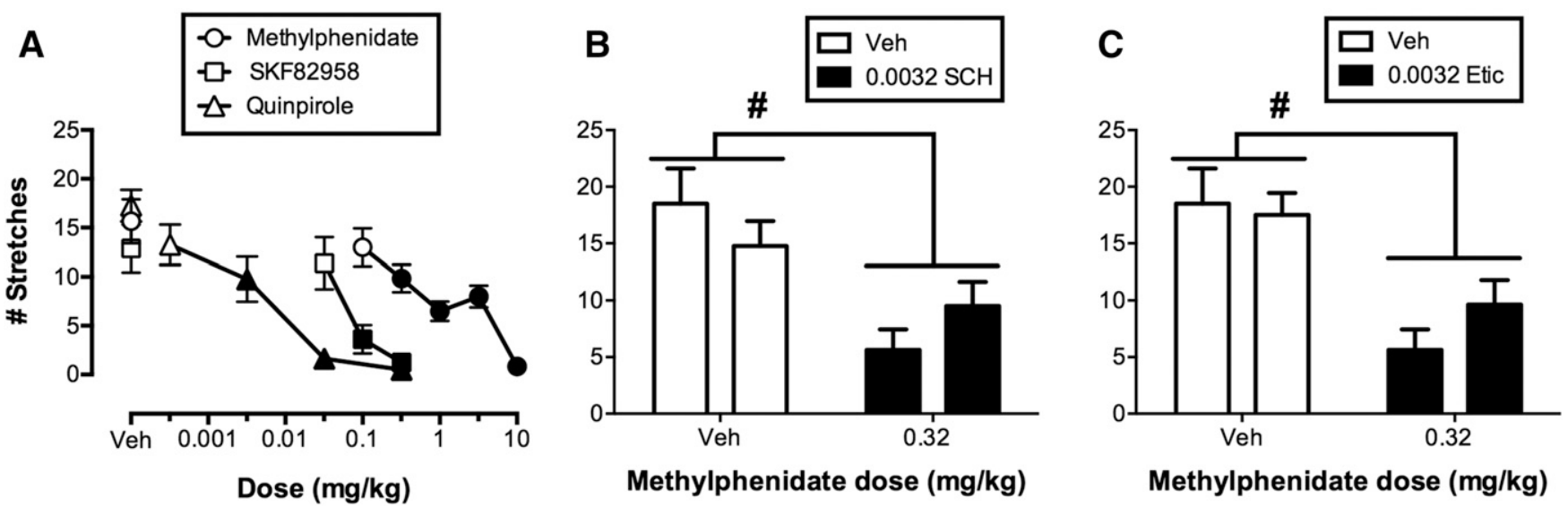

Fig. 4. Effects of test compounds on acid-stimulated stretching. (A) Effects of methylphenidate, SKF82958, and quinpirole on acid-stimulated stretching. Abscissae: dose in mg/kg (log scale). Ordinates: number of stretches per 30 minutes. Filled symbols show significant difference from the respective vehicle (Veh) as determined by a repeated-measures one-way ANOVA followed by Dunnett's post-hoc test $(P<0.05)$. (B and C) ${ }^{\#}$ Significant main effect of methylphenidate dose as determined by two-way ANOVA. All points show mean \pm S.E.M. of six to eight rats, and identical data are used for antagonist vehicle in (B) and (C) because both drugs used the same vehicle. Statistical results are as follows. (A) Significant effect of dose for methylphenidate $[\mathrm{F}(5,25)=22.04, P<0.01]$, SKF82958 $[\mathrm{F}(3,21)=10.32, P<0.01]$, and quinpirole $[\mathrm{F}(4,28)=21.01, P<0.01]$. (B) Significant main effects of methylphenidate dose $[\mathrm{F}(1,7)=13.82, P<0.01]$ but not of SCH39166 (SCH) dose, and the interaction was also not significant. (C) Significant main effects of methylphenidate dose $[\mathrm{F}(1,7)=11.27, P<0.05]$ but not of eticlopride (Etic) dose, and the interaction was also not significant.

alleviated by dopamine but not norepinephrine uptake inhibitors (Rosenberg et al., 2013). Second, methylphenidate antinociception in the assay of acid-depressed ICSS was completely blocked by the D1-like dopamine receptor antagonist SCH39166. The D2-like antagonist eticlopride also appeared to attenuate methylphenidate antinociception, but statistical analysis indicated a main effect of eticlopride to decrease ICSS regardless of the presence or absence of methylphenidate. In the assay of acid-stimulated stretching, experiments to examine antagonism of methylphenidate by SCH39166 and eticlopride could not be confidently interpreted and were inconclusive. The SCH39166 and eticlopride doses tested in the ICSS procedure $(0.01 \mathrm{mg} / \mathrm{kg}$ for both antagonists) failed to block methylphenidate antinociception in the stretching procedure; however, these antagonist doses decreased stretching on their own, and these direct effects of the antagonists may have obscured any antagonism of methylphenidate. Lower doses of each antagonist were also tested that did not have significant direct effects, but these lower doses were not sufficient to block methylphenidate antinociception. Overall, the strongest conclusion that can be drawn from antagonism studies is that D1 receptor activation is necessary for methylphenidate antinociception in the assay of acid-depressed ICSS.

In support of this conclusion, studies with selective dopamine receptor agonists suggested that D1-like receptor activation is also sufficient for antinociception in the assay of acid-depressed ICSS. Similar to methylphenidate, the D1-selective agonist SKF82958 produced a dose-dependent, complete, and SCH39166-reversible blockade of acid-induced decreases in ICSS. Additionally, the mean $\mathrm{ED}_{50}$ value for SKF82958 was lower in the assay of acid-depressed ICSS than of acid-stimulated stretching, although this potency difference was smaller for SKF82958 than for methylphenidate and did not meet the criterion for statistical significance. In contrast to methylphenidate and SKF82958, the D2-like agonists only exacerbated acid-induced decreases in ICSS. Moreover, quinpirole doses that exacerbated acid-induced decreases in ICSS also reduced acid-stimulated stretching, suggesting that apparent quinpirole antinociception in the latter assay may reflect general motor impairment rather than reduced sensitivity to the noxious stimulus. Taken together, these results suggest that D1-like receptor activation is both sufficient to relieve acid-induced decreases in ICSS in rats and necessary for methylphenidate relief of acid-depressed ICSS. Conversely, D2-like receptor activation appears to produce nonselective behavioral disruption.

The present results build on previous studies that examined effects of dopamine receptor agonists in conventional preclinical assays of pain-stimulated behaviors. For example, intraplantar formalin-stimulated behaviors in rats were blocked by both SKF82958 and quinpirole (Morgan and Franklin, 1991; Munro, 2007). The present results provide additional evidence for the effectiveness of SKF82958 to block pain-stimulated behavior in rats (i.e., by blocking acidstimulated stretching) and further suggest that SKF82958 can also alleviate pain-related behavioral depression (i.e., by blocking acid-induced depression of ICSS). This effectiveness in alleviating both pain-stimulated and pain-depressed behaviors is similar to the pattern of effects produced by clinically effective analgesics including mu opioid receptor agonists and nonsteroidal anti-inflammatory drugs (Negus et al., 2012a; Negus, 2013; Altarifi et al., 2015). The effectiveness of quinpirole to block formalin-stimulated behaviors also agrees with the present finding that quinpirole blocked acid-stimulated stretching and with other studies showing apparent antinociception by D2-like agonists in other assays of pain-stimulated behavior (Paalzow and Paalzow, 1983; Barasi and Duggal, 1985; Michael-Titus et al., 1990; Morgan and Franklin, 1991; Munro, 2007); however, as noted earlier, the present results suggest that these effects of D2-like agonists on pain-stimulated behaviors reflect general behavioral suppression rather than decreased pain sensitivity.

In addition to blocking acid-induced decreases in ICSS, methylphenidate also increased control ICSS when methylphenidate was administered alone without acid. Druginduced increases in ICSS are predictive of abuse liability (Negus and Miller, 2014), and methylphenidate is one of 
several dopamine transporter inhibitors that is scheduled by the Food and Drug Administration and has well established abuse liability in humans (Weyandt et al., 2016). Centrally acting D1-like agonists are not available clinically, and their abuse potential in humans is uncertain, but SKF82958 increases ICSS and produces other preclinical signs of abuse liability (Weed and Woolverton, 1995; Lazenka et al., 2016). These results raise the possibility that methylphenidate and SKF82958 effects on pain-depressed behavior may reflect nonselective behavioral stimulation associated with abuse liability rather than attenuation of sensitivity to the acid noxious stimulus. However, two findings argue against this possibility. First, both methylphenidate (present study) and SKF82958 (Lazenka et al., 2016) were approximately 3-fold more potent in blocking acid-induced decreases in ICSS than in increasing control ICSS. Thus, acid-induced decreases in ICSS could be blocked by relatively low drug doses that did not enhance control ICSS. Second, both methylphenidate and SKF82958 decreased acid-stimulated stretching rather than exacerbating it. Thus, any behavioral stimulant effects of methylphenidate and SKF82958 did not extend to stimulation of acid-induced stretching behavior.

In this study, ICSS was maintained by stimulation of the lateral hypothalamus because stimulation at this site activates local neuronal cell bodies and/or descending myelinated axons that provide excitatory input to mesolimbic dopaminergic neurons in the ventral tegmental area, and lateral hypothalamic ICSS is sensitive to manipulations that decrease mesolimbic dopamine signaling (Carlezon and Chartoff, 2007; Negus and Miller, 2014). We found previously that intraperitoneal lactic acid injection produced an analgesic-reversible depression in both ICSS and mesolimbic dopamine release (Leitl et al., 2014), and results of the present study suggest that stimulation of D1-like receptors can produce analgesic-like effects. However, ICSS can also be maintained by stimulation of other brain sites (Carlezon and Chartoff, 2007; Negus and Miller, 2014), and it remains to be determined if D1-like receptor activation would be sufficient to block pain-related decreases in either ICSS at other brain sites or other behaviors that do not involve direct stimulation of mesolimbic dopamine neurons.

In conclusion, this study provides evidence that dopamine transporter inhibitors and D1-like dopamine receptor agonists may relieve pain-related behavioral depression. Dopamine transporter inhibitors and/or D1-like agonists are unlikely to have utility as stand-alone treatment of pain, but their use may warrant consideration under circumstances in which relief of pain-depressed behavior is therapeutically advantageous. For example, exercise is often a part of multimodal pain treatment (Canadian Agency for Drugs and Technologies in Health, 2016; Laubenstein and Beissner, 2016), but behavioral impairment produced by either pain or sedative medications may interfere with patient participation. The benefits of exercise in pain treatment appear to involve mesolimbic dopaminergic mechanisms (Wakaizumi et al., 2016), and drugs such as methylphenidate or SKF82958 may be useful as adjuncts to physical therapy.

\section{Authorship Contributions}

Participated in research design: Lazenka, Freitas, Negus.

Conducted experiments: Lazenka, Freitas, Henck.

Performed data analysis: Lazenka, Freitas, Henck, Negus.

Wrote or contributed to the writing of the manuscript: Negus, Freitas, Negus.

\section{References}

Altarifi AA, Rice KC, and Negus SS (2015) Effects of $\mu$-opioid receptor agonists in assays of acute pain-stimulated and pain-depressed behavior in male rats: role of $\mu$-agonist efficacy and noxious stimulus intensity. $J$ Pharmacol Exp Ther 352: $208-217$.

Altier N and Stewart J (1999) The role of dopamine in the nucleus accumbens in analgesia. Life Sci 65:2269-2287.

Apkarian AV, Baliki MN, and Farmer MA (2013) Predicting transition to chronic pain. Curr Opin Neurol 26:360-367.

Bair MJ, Robinson RL, Katon W, and Kroenke K (2003) Depression and pain comorbidity: a literature review. Arch Intern Med 163:2433-2445.

Baliki MN, Geha PY, Fields HL, and Apkarian AV (2010) Predicting value of pain and analgesia: nucleus accumbens response to noxious stimuli changes in the presence of chronic pain. Neuron 66:149-160.

Barasi S and Duggal KN (1985) The effect of local and systemic application of dopaminergic agents on tail flick latency in the rat. Eur $J$ Pharmacol 117:287-294.

Bauer CT, Banks ML, Blough BE, and Negus SS (2013) Use of intracranial selfstimulation to evaluate abuse-related and abuse-limiting effects of monoamine releasers in rats. $\mathrm{Br} J$ Pharmacol 168:850-862.

Becerra L, Breiter HC, Wise R, Gonzalez RG, and Borsook D (2001) Reward circuitry activation by noxious thermal stimuli. Neuron 32:927-946.

Beydoun A and Backonja MM (2003) Mechanistic stratification of antineuralgic agents. J Pain Symptom Manage 25(5, Suppl)S18-S30.

Bonano JS, Glennon RA, De Felice LJ, Banks ML, and Negus SS (2014) Abuserelated and abuse-limiting effects of methcathinone and the synthetic "bath salts" cathinone analogs methylenedioxypyrovalerone (MDPV), methylone and mephedrone on intracranial self-stimulation in rats. Psychopharmacology (Berl) 231: 199-207.

Bruera E, Brenneis C, Paterson AH, and MacDonald RN (1989) Use of methylphenidate as an adjuvant to narcotic analgesics in patients with advanced cancer. J Pain Symptom Manage 4:3-6.

Brust TF, Morgenweck J, Kim SA, Rose JH, Locke JL, Schmid CL, Zhou L, Stahl EL, Cameron MD, Scarry SM, et al. (2016) Biased agonists of the kappa opioid receptor suppress pain and itch without causing sedation or dysphoria. Sci Signal 9:ra117.

Burrill DY, Goetzl FR, and Ivy AC (1944) The pain threshold raising effects of amphetamine. J Dent Res 23:337-344.

Caine SB and Koob GF (1994) Effects of dopamine D-1 and D-2 antagonists on cocaine self-administration under different schedules of reinforcement in the rat. J Pharmacol Exp Ther 270:209-218.

Canadian Agency for Drugs and Technologies in Health (2016) Physical Therapy Treatments for Chronic Non-Cancer Pain: A Review of Guidelines, Ottawa, ON, Canada.

Carlezon, JrWA and Chartoff EH (2007) Intracranial self-stimulation (ICSS) in rodents to study the neurobiology of motivation. Nat Protoc 2:2987-2995.

Chudler EH and Dong WK (1995) The role of the basal ganglia in nociception and pain. Pain 60:3-38.

Chudler EH and Lu Y (2008) Nociceptive behavioral responses to chemical, thermal and mechanical stimulation after unilateral, intrastriatal administration of 6-hydroxydopamine. Brain Res 1213:41-47.

Cury RG, Galhardoni R, Fonoff ET, Perez Lloret S, Dos Santos Ghilardi MG, Barbosa ER, Teixeira MJ, and Ciampi de Andrade D (2016) Sensory abnormalities and pain in Parkinson disease and its modulation by treatment of motor symptoms. Eur $J$ Pain 20:151-165.

Dalal S and Melzack R (1998) Psychostimulant drugs potentiate morphine analgesia in the formalin test. J Pain Symptom Manage 16:230-239.

Dickey RP and Minton JP (1972) Levodopa relief of bone pain from breast cancer $N$ Engl J Med 286:843

Dourado M, Cardoso-Cruz H, Monteiro C, and Galhardo V (2016) Effect of Motor Impairment on Analgesic Efficacy of Dopamine D2/3 Receptors in a Rat Model of Neuropathy. J Exp Neurosci 10:51-57.

Dworkin RH, Turk DC, Farrar JT, Haythornthwaite JA, Jensen MP, Katz NP, Kerns RD, Stucki G, Allen RR, Bellamy N, et al.; IMMPACT (2005) Core outcome measures for chronic pain clinical trials: IMMPACT recommendations. Pain 113:9-19.

Ertas M, Sagduyu A, Arac N, Uludag B, and Ertekin C (1998) Use of levodopa to relieve pain from painful symmetrical diabetic polyneuropathy. Pain 75:257-259.

Ford B (2009) Parkinson disease: Pain in Parkinson disease: the hidden epidemic Nat Rev Neurol 5:242-243.

Francis TC and Lobo MK (2017) Emerging role for nucleus accumbens medium spiny neuron subtypes in depression. Biol Psychiatry 81:645-653.

Freitas KC, Carroll FI, and Negus SS (2015) Effects of nicotinic acetylcholine receptor agonists in assays of acute pain-stimulated and pain-depressed behaviors in rats. J Pharmacol Exp Ther 355:341-350.

Freitas K, Carroll FI, and Negus SS (2016) Comparison of effects produced by nicotine and the $\alpha 4 \beta 2$-selective agonist 5-I-A-85380 on intracranial self-stimulation in rats. Exp Clin Psychopharmacol 24:65-76.

Gatch MB, Negus SS, and Mello NK (1998) Antinociceptive effects of monoamine reuptake inhibitors administered alone or in combination with mu opioid agonists in rhesus monkeys. Psychopharmacology (Berl) 135:99-106.

Gatch MB, Negus SS, and Mello NK (1999) Antinociceptive effects of cocaine in rhesus monkeys. Pharmacol Biochem Behav 62:291-297.

Gerdelat-Mas A, Simonetta-Moreau M, Thalamas C, Ory-Magne F, Slaoui T, Rascol $\mathrm{O}$, and Brefel-Courbon C (2007) Levodopa raises objective pain threshold in Parkinson's disease: a RIII reflex study. J Neurol Neurosurg Psychiatry 78:1140-1142.

Halladay LR, Iñiguez SD, Furqan F, Previte MC, Chisum AM, and Crawford CA (2009) Methylphenidate potentiates morphine-induced antinociception, hyperthermia, and locomotor activity in young adult rats. Pharmacol Biochem Behav 92 : 190-196.

Hillhouse TM and Negus SS (2016) Effects of the noncompetitive N-methyl-daspartate receptor antagonists ketamine and MK-801 on pain-stimulated and pain-depressed behaviour in rats. Eur J Pain 20:1229-1240. 
Jensen KB, Srinivasan P, Spaeth R, Tan Y, Kosek E, Petzke F, Carville S, Fransson P, Marcus H, Williams SC, et al. (2013) Overlapping structural and functional brain changes in patients with long-term exposure to fibromyalgia pain. Arthritis Rheum 65:3293-3303.

Kwilasz AJ, Abdullah RA, Poklis JL, Lichtman AH, and Negus SS (2014) Effects of the fatty acid amide hydrolase inhibitor URB597 on pain-stimulated and paindepressed behavior in rats. Behav Pharmacol 25:119-129.

Kwilasz AJ and Negus SS (2012) Dissociable effects of the cannabinoid receptor agonists $\Delta 9$-tetrahydrocannabinol and CP55940 on pain-stimulated versus paindepressed behavior in rats. J Pharmacol Exp Ther 343:389-400.

Laubenstein S and Beissner K (2016) Exercise and Movement-based Therapies in Geriatric Pain Management. Clin Geriatr Med 32:737-762.

Lazenka MF, Legakis LP, and Negus SS (2016) Opposing effects of dopamine D1- and D2-like agonists on intracranial self-stimulation in male rats. Exp Clin Psychopharmacol 24:193-205.

Ledermann K, Jenewein J, Sprott H, Hasler G, Schnyder U, Warnock G, Johayem A Kollias S, Buck A, and Martin-Soelch C (2016) Relation of dopamine receptor 2 binding to pain perception in female fibromyalgia patients with and without depression-A $\left[{ }^{11} \mathrm{C}\right]$ raclopride PET-study. Eur Neuropsychopharmacol 26:320-330.

Leitl MD, Onvani S, Bowers MS, Cheng K, Rice KC, Carlezon, JrWA, Banks ML, and Negus SS (2014) Pain-related depression of the mesolimbic dopamine system in rats: expression, blockade by analgesics, and role of endogenous к-opioids. Neuropsychopharmacology 39:614-624.

Li SM, Campbell BL, and Katz JL (2006) Interactions of cocaine with dopamine uptake inhibitors or dopamine releasers in rats discriminating cocaine. $J$ Pharmacol Exp Ther 317:1088-1096.

McLaughlin G, Morris N, Kavanagh PV, Power JD, Dowling G, Twamley B, O’Brien J, Hessman G, Murphy B, and Walther D, et al. (2017) Analytical characterization and pharmacological evaluation of the new psychoactive substance 4-fluoromethylphenidate $(4 \mathrm{~F}-\mathrm{MPH})$ and differentiation between the $( \pm)$-threo and $( \pm)$-erythro diastereomers. Drug Test Anal 9:347-357.

Michael-Titus A, Bousselmame R, and Costentin J (1990) Stimulation of dopamine D2 receptors induces an analgesia involving an opioidergic but non enkephalinergic link. Eur J Pharmacol 187:201-207.

Miller LL, Leitl MD, Banks ML, Blough BE, and Negus SS (2015) Effects of the triple monoamine uptake inhibitor amitifadine on pain-related depression of behavior and mesolimbic dopamine release in rats. Pain 156:175-184.

Morgan MJ and Franklin KB (1991) Dopamine receptor subtypes and formalin test analgesia. Pharmacol Biochem Behav 40:317-322.

Mücke M, Cuhls H, Peuckmann-Post V, Minton O, Stone P, and Radbruch L; Mochamat (2015) Pharmacological treatments for fatigue associated with palliative care. Cochrane Database Syst Rev (5):CD006788.

Munro G (2007) Dopamine $\mathrm{D}(1)$ and $\mathrm{D}(2)$ receptor agonism enhances antinociception mediated by the serotonin and noradrenaline reuptake inhibitor duloxetine in the rat formalin test. Eur J Pharmacol 575:66-74.

Nahin RL (2015) Estimates of pain prevalence and severity in adults: United States, 2012. J Pain 16:769-780.

National Research Council (U.S.) (2011) Guide for the care and use of laboratory animals, Ed. 8th. National Academies Press, Washington, DC.

Negus SS (2013) Expression and treatment of pain-related behavioral depression. Lab Anim (NY) 42:292-300.

Negus SS and Miller LL (2014) Intracranial self-stimulation to evaluate abuse potential of drugs. Pharmacol Rev 66:869-917.

Negus SS, Morrissey EM, Rosenberg M, Cheng K, and Rice KC (2010) Effects of kappa opioids in an assay of pain-depressed intracranial self-stimulation in rats. Psychopharmacology (Berl) 210:149-159.
Negus SS, O'Connell R, Morrissey E, Cheng K, and Rice KC (2012a) Effects of peripherally restricted $\kappa$ opioid receptor agonists on pain-related stimulation and depression of behavior in rats. $J$ Pharmacol Exp Ther 340:501-509.

Negus SS, Rosenberg MB, Altarifi AA, O'Connell RH, Folk JE, and Rice KC (2012b) Effects of the $\delta$ opioid receptor agonist SNC80 on pain-related depression of intracranial self-stimulation (ICSS) in rats. J Pain 13:317-327.

Negus SS, Vanderah TW, Brandt MR, Bilsky EJ, Becerra L, and Borsook D (2006) Preclinical assessment of candidate analgesic drugs: recent advances and future challenges. J Pharmacol Exp Ther 319:507-514.

Paalzow GH and Paalzow LK (1983) Opposing effects of apomorphine on pain in rats. Evaluation of the dose-response curve. Eur $J$ Pharmacol 88:27-35.

Paxinos G and Watson C (1998) The rat brain in stereotaxic coordinates, 4th Ed., Academic Press, San Diego.

Pereira Do Carmo G, Stevenson GW, Carlezon WA, and Negus SS (2009) Effects of pain- and analgesia-related manipulations on intracranial self-stimulation in rats: further studies on pain-depressed behavior. Pain 144:170-177.

Rosenberg MB, Carroll FI, and Negus SS (2013) Effects of monoamine reuptake inhibitors in assays of acute pain-stimulated and pain-depressed behavior in rats $J$ Pain 14:246-259.

Saadé NE, Atweh SF, Bahuth NB, and Jabbur SJ (1997) Augmentation of nociceptive reflexes and chronic deafferentation pain by chemical lesions of either dopaminergic terminals or midbrain dopaminergic neurons. Brain Res 751:1-12.

Semenchuk MR, Sherman S, and Davis B (2001) Double-blind, randomized trial of bupropion SR for the treatment of neuropathic pain. Neurology 57:1583-1588.

Sophie M and Ford B (2012) Management of pain in Parkinson's disease. CNS Drugs 26:937-948.

Taylor AM, Becker S, Schweinhardt P, and Cahill C (2016) Mesolimbic dopamine signaling in acute and chronic pain: implications for motivation, analgesia, and addiction. Pain 157:1194-1198.

Treister R, Eisenberg E, Demeter N, and Pud D (2015) Alterations in pain response are partially reversed by methylphenidate (Ritalin) in adults with attention deficit hyperactivity disorder (ADHD). Pain Pract 15:4-11.

van Hecke O, Torrance N, and Smith BH (2013) Chronic pain epidemiology and its clinical relevance. Br J Anaesth 111:13-18.

Wakaizumi K, Kondo T, Hamada Y, Narita M, Kawabe R, Narita H, Watanabe M, Kato S, Senba E, Kobayashi K, et al. (2016) Involvement of mesolimbic dopaminergic network in neuropathic pain relief by treadmill exercise: A study for specific neural control with Gi-DREADD in mice. Mol Pain 12:12.

Weed MR and Woolverton WL (1995) The reinforcing effects of dopamine D1 receptor agonists in rhesus monkeys. J Pharmacol Exp Ther 275:1367-1374.

Weyandt LL, Oster DR, Marraccini ME, Gudmundsdottir BG, Munro BA, Rathkey ES, and McCallum A (2016) Prescription stimulant medication misuse: Where are we and where do we go from here? Exp Clin Psychopharmacol 24:400-414.

Wood PB, Patterson, 2ndJC, Sunderland JJ, Tainter KH, Glabus MF, and Lilien DL (2007) Reduced presynaptic dopamine activity in fibromyalgia syndrome demonstrated with positron emission tomography: a pilot study. J Pain 8:51-58.

Yamamotová A, Fricová J, Rokyta R, and Slamberová R (2016) The effect of combined treatment of opioids with methylphenidate on nociception in rats and pain in human. Physiol Res 65 (Supplementum 5):S567-S575.

Address correspondence to: S. Stevens Negus, Department of Pharmacology and Toxicology, Virginia Commonwealth University, 410 North 12th Street, Richmond, VA 23298. E-mail: sidney.negus@vcuhealth.org 